\title{
Discrimination Evidence for Examining Fourth Grade Students' Learning Disability Problems
}

\author{
Abdulhameed S. Hassan ${ }^{1} \&$ Ibrahim S. Al-Harthy ${ }^{1}$ \\ ${ }^{1}$ Department of Psychology, College of Education, Sultan Qaboos University, Muscat, Oman \\ Correspondence: Ibrahim S. Al-Harthy, Department of Psychology, College of Education, Sultan Qaboos \\ Univeristy, Oman. Tel: 968-9-938-5389. E-mail: ibrahimh@squ.edu.om
}

Received: July 9, 2014

doi:10.5539/jel.v3n3p183

\author{
Accepted: August 4, 2014 Online Published: August 27, 2014 \\ URL: http://dx.doi.org/10.5539/jel.v3n3p183
}

\begin{abstract}
This study investigated the ability of discriminate variables (perceptual-motor, hyperactivity disorder, neurological and psychological skills) to distinguish between normal $(\mathrm{n}=68)$ and students with learning disabilities $(\mathrm{n}=72)$ in fourth grade. Three instruments were developed: perceptual-motor scale, hyperactivity disorder scale, skills test neuropsychiatric. Eight schools were purposely chosen for their collaboration with the College of Education at Sultan Qaboos University. The sample consists of 140 students (68 students with learning disabilities and 73 normal students; 73 males). The results demonstrated a positive significant correlation between perceptual-motor and neurological and psychological skills. In addition, a negative significant correlation was found between hyperactivity disorder, perceptual-motor and neurological and psychological skills. Using discriminate analysis, the study shows that the three developed measurements can discriminate between normal students and students with learning disabilities. We recommend using the three scales on students with learning disabilities for the purpose of early examination. There is a need to conduct a similar study, with other scales, for better examinations.
\end{abstract}

Keywords: learning disability, perceptual-motor, hyperactivity disorder, neurological and psychological skills

\section{Introduction}

Individual differences among learners across all stages of learning have clearly revealed the presence of recreation, innovation, and giftedness among learners. Moreover, a large amount of evidence indicates dysfunction and disabilities among learners in different grades. The learners with learning disabilities become one of the groups receiving the most attention, particularly after including students not suffering from clear disabilities such as blindness, deafness, or any other mental or physical disability (Barratt, 2008). Additionally, the number of learners classified with disabilities is increasing continuously, making them the most representative class of learners with special needs (Heward, 2006).

This gradual increase is supported by statistics presented in 2006 by the USA Department of Education indicating that 2.9 million children in the USA received special education and have been typically classified as learning disabled. According to the statistics published by the National Center for Special Education in 2006, more than $38.7 \%$ of children with learning disabilities do not reach high school, compared to $11 \%$ of the general public. Emerson et al. (2010) stated that "learners with learning disabilities may increase in England to reach 1,198,000 people have learning disabilities. This includes 298,000 children age 0-17; 900,000 adults aged 18+, of whom 191,000 (21\%) are known to learning disabilities services" (p. 6).

It is undeniable that the increase in the number of children with learning disabilities is a threat to the educational system as it endangers the effectiveness of current educational efforts. Therefore, this necessitates the importance of early diagnosis of children with learning disabilities, working on treating them, and immersing them in normal classrooms. Researchers have stressed the need to provide appropriate diagnostic techniques for children with learning disabilities from the early stages of life and to offer effective treatment programs (Morrow, 2005).

The appropriate techniques for diagnosing children with learning disabilities are controversial to the degree that a number of diagnostic approaches have to be taken into consideration (McLeskey \&Waldron, 2011). As a result of this controversy, researchers have dedicated their interests to assessing diagnostic techniques used to discover 
children with learning disabilities. A great body of psychological and educational research has discussed a number of techniques to diagnose those learners through study and analysis (e.g., Westendrop, Hartman, Houwen, Smith, \& Visscher 2011; Womack, 2011). Some of these techniques included tracing and diagnosing academic characteristics by using a variety of methods to provide appropriate treatment (Jop, 2011; Womack, 2011). For example, Jop (2012) noted that all previous studies indicated low academic achievement for this class of learners thus recommending the importance of applying a number of diverse criteria to diagnose and identify students with learning disabilities so that their academic performance is predicted more precisely.

Students with learning disabilities show discrepancy between their actual performance in one or more academic field(s) and their expected performance. The academic learning disabilities are obviously observed not only in students' inability to perform learning tasks, but also in experiencing difficulty following the teacher's directions. In contrast, developmental disabilities (attention, memory, and awareness) resulted in lowering students' motivation in class (Bender, 2002).

Westendrop, Hartman, Houwen, Smith and Visscher (2011) affirmed that the expected performance (developmental characteristics) predicts the link between psychomotor academic performance among students with learning disabilities. The sample included 104 students, aged between 7-12 years, who completed the Psychomotor Skill Test and Academic Skills Scale (Reading, Writing, and Math). Results showed a significant positive relationship between low psychomotor skills and low academic achievement. It is important to note that this correlation between developmental and academic characteristics was interpreted by a number of researchers (e.g., Cullata \& Tompkins, 2003; Jop, 2012). Cullata and Tompkins found that perceptual-motor abilities among students with learning disabilities result from their inability to explain and interpret environmental stimuli received by the senses. Learners, therefore, cannot reach the indications and meanings of those stimuli, particularly if the rhythm or flow of stimuli is rapid and does not match their processing and preparation levels, which is reflected in their low academic achievement. Zhang and Zhang (2003) confirmed this relationship and found that $85 \%$ of a sample of children with learning disabilities had weakness in their perceptual-motor abilities, $59 \%$ had weakness in balancing abilities, and $59 \%$ had weakness in movement coordination. The study recommended the significance of conducting studies and designing programs to treat these perceptual-motor abilities for children between (4-10) years.

In contrast, a number of researchers believe that the roots of learning disabilities stem from neuro-psychological issues, such as hyper activity (Mayes \& Calholl, 2007; Katerina \& Efthymois, 2010). This approach is supported by Exner (2010) who found that ADHD is the core cause of learning disabilities across all school stages up to university level. The Diagnostic and Statistical Manual of Mental Disorders (DSM IV-R, 2000) indicates that ADHD is significantly widespread among school students to reach about 3-7\% of children in schools. These children show attention deficit and hyper activity inconsistent with situation demands in which they are present (Barkley \& Murphy, 2006). It is significant to note that scientific and organized study of ADHD started in 1960 finding that basic indicators include attention deficit, impulsivity, hyper activity, which are widespread among children with learning disabilities (Herbert, 1999). This disorder is considered a chronic biological syndrome related to the nervous system that is not attributed to poverty or inappropriate educational and social environment. Given that, the diagnosis should be based on neuro-psychological scales (Exner, 2010). Hyper activity is seen as a major neuro-psychological disorder among children that needs to be addressed by specialists through neuro-psychological diagnosis scales (DeMarie, Denk, \& Emsthausen, 2003; Medwid, 2002).

The diagnosis of ADD (Attention Deficit Disorder) is a highly important and precise process that requires the collaborative efforts of many individuals, including the child's family (Kelly, 2009). Some studies stress the need to scrutinize the challenging criteria when diagnosing ADHD among students (O'Connel \& Casale, 2004). Indeed, diagnosing those students needs to be as early as possible using precise diagnostic techniques to provide them with appropriate treatments (Lerner, 2000). Although ADD is important when diagnosing students with learning disabilities, others believe that sequential hearing memory is a major contributor in diagnosis. They contend that those children cannot remember items sequentially such as letters, numbers, words, and sounds (Bender, 2001; Zarghi, Mehrinjad, Zail, \& Remezanking, 2012). In fact, short term memory is one of the highest contributing factors for low academic achievement among students with learning disabilities, as well as predicting student's reading comprehension and word recognition (Alloway \& Passolunghi, 2006; Ashbaker, 2000; Ashbaker \& Swanson, 1996; Jerman, 2007; Swanson \& Claudia, 2009).

Memory disorders are correlated with ADD and awareness process disorders. Thus, an individual's attention span, ability to pay attention selectively, awareness processes, and interpretation of stimuli are all basic input elements in memory processes (Coullet, Leclercg, Morni, \& Azouvi, 2002; Levine, 2002). Supporting this 
correlation is the medical point of view that indicates learning disability as a disorder in some of the nervous system functions therefore affecting the individual's ability to read, write, spell, receive stimuli, remember and organize information, and make calculations (Lerner, 2000). This view is similar to the findings of some research that attributed low academic achievement among students with learning disabilities to a simple defect in brain cells. Research stresses the importance of neuro-psychological analysis by which these disabilities are discovered (Anzelmo-Skelton, 2006; Lord-Meas \& Obzurt, 1996; Mazzocco, 2005). Therefore, any damage or defect in the central nervous system with the student can be reflected in behavior such as a deficit or disorder in senses, cognition, achievement, and motor skills.

One of the most outstanding approaches for interpreting learning disabilities is the neuro-psychological approach that focuses on mental processes. This approach is observed by psychologists to understand sensing, cognitive, and learning abilities and processes used by the individual. Willams and McGee (1996) investigated the developmental learning disabilities (attention, awareness, memory) in children between 9-10 years old. The study found that students with learning disabilities have weaknesses in perceptual-motor abilities and ADD. These findings were replicated by Waldron and Saphire (1992). Based on these studies, it appears that the concept of learning disabilities comprises the incomplete ability to pay attention, remember, or do calculations. Most of the children with learning disabilities suffer from awareness disabilities that may lead to a mild dysfunction in brain processes related to the child's learning (Liddel \& Rasmussen, 2005; Mazzocco, 2005; Smith, 2004).

Researchers in the field of assessment tools are motivated to diagnose developmental disabilities consistent with scale designing criteria, obtaining data related to the child's behavior at school, and his/her achievement (Kelly, 2009). For instance, when measuring the perceptual-motor abilities, some criteria must be followed. The first criterion is taking into account the organized observations of children when diagnosing those with learning disabilities, those late at school, and normal achieving children in the early stages of school. This diagnosis aims to discover any deficits in perceptual-motor abilities development, locating areas of motor-awareness problems, and noticing dysfunctions in motor-awareness behavior in a series of performances. As most children with learning disabilities suffer from a nervous disorder, the second criterion focuses on perceptual-motor abilities that cause the child's inability to learn. This concept was garnered by a number of theories presented in this area (e.g., Barsch, 1967; Delacato \& Doman, 1966; Frostig, 1964; Getman, 1964; Hasan, 2009; Kephart, 1971, 1972). The third criterion includes the application of known assessment tools that have psychometric properties to measure motor-awareness abilities according to the aforementioned motor-awareness theories. One important assessment tools is the testing battery designed by Jean Ayers (known as Southern California Perception Motor Tests), Frostig's Marian Frostig Development of Visual Perception, Diton's scale of motor-sensing awareness, and The Purdue Perceptual-Motor Survey constructed in the USA by Eugene G. Roach and Newell C. Kephart (Bader \& Sayyed, 2001; Hassan, 2009; Rubi, 1991).

Relating to the diagnosis of children with ADHD, the American Academy of Pediatrics has placed a number of criteria that must be taken into consideration when diagnosing children with ADHD between the ages of 6 to12 years. The first criterion includes ADHD, school problems, low achievement, problems with teachers and family members, problems with other people, and any other family issue. The second criterion includes directing questions to parents or through surveys concentrating on school environment and behavior problems that might cause symptoms of this disorder. The third criterion concerns the use of the criteria listed in the (DSM IV-R, 2000). As indicated, symptoms of this disorder appear in two different classes and these symptoms impact the child's socialization and leads to under-achievement, particularly if it lasts for more than 6 months. The fourth criterion focuses on recruiting data available on ADHD symptoms in different cases, start of the symptoms and their extent, and the range of academic and social deficits. The fifth criterion includes the importance of diagnosing other disorders along with ADHD. The last criterion asserts that the specialist should be aware of any resembling symptoms between some normal children and children with ADHD which are in fact not attributable to ADHD (Monastra, 2008; Rief, 2008; Turkington \& Harris, 2006).

In relation to the criteria of diagnosing mental processes related to different types of memory that have nervous system roots (sequential memory, sequential-term memory, ability to differentiate, and audio visual integration), scientists assert precision diagnosis. Scientists contend that these mental processes can indicate level of proficiency in visual and psychological processes needed by the child before school until the age of 9 even though these diagnoses may not have a direct relationship with learning, reading, and writing. It is significant, though, to bear in mind that being late in developing these two types of memory (SM \& STM) leads to lateness in comprehension and learning with the child. A great body of research has supported this claim, one of which indicates that children with diverse achievement abilities may have various styles in the use of these memories, 
although the relationship between different memories is intertwined (Buckner \& Wheeler, 2001; Rohi \& Pratt, 1995; Swanson, 1994).

Neuro-psychological diagnoses are various, one of which is neuron-screening diagnosis. Gerstmann (1924), as the pioneer of this diagnosis, mentioned that the neuron-screening occurs with minor injuries in the left hemisphere of the brain and include four symptoms: finger agnosia, dysgraphia, dyscalculia, and right-left disorientation._A number of researchers have advocated this conceptualization in their research of children with learning disabilities including Fabian and Jacobs, (1981) who applied the Bender Gestalt Test 1976 and Quick Neurological Screening Test (QNST) in 1974 to diagnose children with learning disabilities between 8 to 12 years old. On the other hand, Beaton, Edwards, and Peggie (2006) used Castles and Colthear's (1976) test to diagnose children with reading disabilities from age 6 or older.

After reviewing the previous literature, there is a need to provide assessment tools that target differentiating abilities for early diagnosis of children with learning disabilities in the first cycle of school. This tool focuses on perceptual-motor abilities, ADHD, dysfunction in mental processes, such as attention, memory and awareness. This research aims to answer the following questions: first, what is the differentiating evidence for scores of students with learning disabilities in the first cycle of school (1-4) on the Perceptual-Motor abilities Scale, ADHD Scale, and psychological and IQ Skills Scale according to their learning disability classification? Second, what is the differentiating evidence for scores of students with learning disabilities in the first cycle of school (1-4) on the Perceptual-Motor abilities Scale, ADHD Scale, and psychological and IQ Skills Scale according to gender?

\section{Methodology}

\subsection{Sample}

The population for the current study is fourth grade students, both normal and learning disabled, from basic education schools in Muscat/Oman during the academic year of 2012-2013. Eight schools were purposely chosen for their collaboration with the College of Education at Sultan Qaboos University. The sample consists of 140 students (68 students with learning disabilities and 73 normal students; 73 males). It is important to note that these students with learning disabilities were examined using the Otis-Lennon Test to measure their IQ, codified on the Omani environment and through achievement tests in reading and math subjects created by the Ministry of Education in the Sultanate of Oman.

\subsection{Instruments}

Perceptual-Motor Survey. Screening Bordeaux Scale for perceptual- motor survey developed by Newell Kephart and Eugene Roche and known as The Purdue Perceptual Motor Survey was used in this study. The scale terms have been designed on the basis of notes from children with learning difficulties, low achievers and normal academic achievers, in elementary classes. This aims to uncover some dysfunction regarding their perceptual-motor growth, to identify the perceptual-motor problems areas among low achievers, and to provide an opportunity to observe the perceptual-motor behaviors in a chain of performances. Consequently, we can classify the problems that need special treatment.

The scale consists of 31 items; 11 items represent sub-tests distributed on five different fields. (1) Balance and posture covers walking board test and jumping test measuring control, body perception and kinetic rhythm. (2) Body image and differentiation involves identification of body, imitation of movements, obstacle course, angles in the snow, and Kraus-Weber. (3) Perceptual-Motor Match Domain contains two tests: Chalkboard Test and Rhythmic Writing. (4) Ocular Control Domain. (5) Form Perception Domain.

This test consists of geometric shapes drawn on separate cards. The child is required to draw these shapes on a sheet of white paper. These shapes are square, triangle, rhomboid horizontal, rhomboid vertical oblong divided by cross lines, and two crossing lines. Evaluation of this test comprises shape and the arrangement. Children aged between 5- 5.11 months are tested with shapes 1 to 4 while children aged 6 to 6.11 months are tested with shapes 1 to 5. Children 7 years and above are tested with all the shapes. The estimations of 1,2,3,4 ranges for each capacity of the five domains. This measure has high reliability and validity and was first assessed in Oman in 2009 using various techniques such as Content Validity, Criterion Validity, Construction Validity, Discrimination Validity as well as Cronbach's Alpha and test-retest method. Regarding reliability, this study had acceptable internal consistency (Cronbach's Alpha) with a reliability coefficient of 0.83 .

Measure for attention deficit, hyperactivity and impulsivity. This measure was finalized with reference to the DSM IV-R (2000) and NICHQ Vanderbilt Assessment Scale (Wolraich, 2002). Accordingly, the measure consists of 22 statements answered by the teacher, chosen because (Kindle, 2009) the writings and behaviors of teachers are 
considered the best sources for data. The questionnaire is distributed over three factors (attention deficit, hyperactivity, and impulsivity). Respondents respond to each item by choosing one of four possible alternatives (Always, Often, Sometime, and Rarely) which were assigned scores 1,2,3 and 4 respectively. The validity of the questionnaire was examined using the strategy of panel validity. Also, construct validity was examined using exploratory factor analysis with principle components and orthogonal rotation which revealed two factors, both with an eigenvalue greater than 1 . The two factors explained $52.388 \%$ of the total variance extracted. The first factor included 11 items with an eigenvalue of 8.879 and $30.402 \%$ of the total variance extracted. The second factor included 9 items with an eigenvalue of 2.639 and 21.986 of the total variance extracted. Appendix 1 shows the matrix of extracted factors and their item loadings after orthogonal rotation.

Neurological and psychological test. This study depends on neurological and psychological tests created for the Arab environment (Al Sharbati, 1985). These tests involve groups of neurological tests for 15-20 minutes, and are differentiated by their efficiency and their great affinity in distinguishing between children who are more vulnerable to learning disabilities than other normal children. These tests have five types, each characterized by its assessment of 1,2,3,4,5, explained as follows:

Finger Agnosia Test. The child's performance in this test will imply if a child has affinity for distinguishing the sequence of his/her fingers and in recalling numbers correctly. Hence, the child's performance will show if there is an attention deficiency.

Finger Discrimination Test. During this test, a child does not use his/her verbal abilities as in the Finger Agnosia Test. This test is conducted by pointing fingers and children with poor performance have a problem in fundamental cognitive functions, such as selective attention, vigilance attention and the many other types of memory.

Graphiesthesia Test. This tests a child's verbal abilities without a need for the child to know how to write numbers. In this test, it is possible to use the technique of drawing some shapes on the child's palm. Poor performance in this test means weak attention and weak comprehension and lack of awareness of body parts.

Sequential Organization Test. This test is used in investigating the sequential organization and successive memory as both are major components of the education process and of learning reading and writing in the early stages of school.

Finger Apraxia Test. This test is used to measure a child's ability for writing and pencil-holding assessing attention deficiency, concentration and short-term memory.

Test validity was obtained through a number of specialists' referees, while the reliability coefficient $(0.76)$ was obtained through test-retest with a two week duration between.

\section{Results}

Discriminate analyses were used to answer the two questions for this study. In order to investigate the relationship between the three scales, a correlation matrix is depicted in Table 1:

Table 1. Matrix of correlation coefficients between the three scales

\begin{tabular}{llll}
\hline Scale & $\begin{array}{l}\text { Perceptual-Motor } \\
\text { Abilities }\end{array}$ & $\begin{array}{l}\text { Neurological- } \\
\text { Psychological Skills }\end{array}$ & $\begin{array}{l}\text { Attention Deficit, Hyperactivity } \\
\text { and Impulsivity }\end{array}$ \\
\hline $\begin{array}{l}\text { Perceptual-Motor Abilities } \\
\begin{array}{l}\text { Neurological Psychological } \\
\text { Skills }\end{array}\end{array}$ & 1.00 & $0.650^{* *}$ & $-0.373^{* *}$ \\
$\begin{array}{l}\text { Attention Deficit, Hyperactivity } \\
\text { and Impulsivity }\end{array}$ & 1.00 & $-0.479^{* *}$ \\
\hline
\end{tabular}

Note. ${ }^{* *}$ level of significance $(\mathrm{p}<0.05 \mathrm{a})$.

The correlation coefficients reveal a positive relationship between perceptual-motor abilities and neurological psychological skills. Also, there is a negative correlation between cognitive-kinetic abilities, neurological-psychological skills and attention deficiency, hyperactivity and impulsivity.

To answer the first question, it is important to examine differences in the grade averages of normal students and the students with learning disabilities across the three scales. First, using means and standard deviations, we 
examined the grades of the children by the three scales. Each sample was examined: the whole sample, the sample of students with learning disabilities and the sample of normal students, as shown in Table 2.

Table 2. Means and standard deviations for the participants by sample across the three scales

\begin{tabular}{lllllll}
\hline Sample Scales & \multicolumn{2}{c}{$\begin{array}{c}\text { Perceptual-Motor } \\
\text { Abilities }\end{array}$} & \multicolumn{2}{c}{$\begin{array}{c}\text { Neurological } \\
\text { Psychological Skills }\end{array}$} & \multicolumn{2}{c}{$\begin{array}{c}\text { Attention Deficit, } \\
\text { Hyperactivity and Impulsivity }\end{array}$} \\
\cline { 2 - 7 } & $\mathrm{M}$ & $\mathrm{SD}$ & $\mathrm{M}$ & $\mathrm{SD}$ & $\mathrm{M}$ & $\mathrm{SD}$ \\
\hline Learning Difficulties & 2.521 & 0.438 & 2.579 & 0.495 & 3.491 & 0.638 \\
Normal & 3.407 & 0.412 & 4.256 & 0.426 & 2.710 & 0.558 \\
All & 2.977 & 0.614 & 3.441 & 0.958 & 3.089 & 0.713 \\
\hline
\end{tabular}

Then, we computed a discriminate analysis of the students with learning disabilities and normal students on the three scales, using SPSS as shown in Table (3).

Table 3. Discriminate analysis results for the three scales

\begin{tabular}{llll}
\hline Scales & $\begin{array}{l}\text { Test Grade } \\
\text { Wilks Lamda }\end{array}$ & F Value & $\mathrm{p}$ \\
& 0.475 & 152.301 & 0.000 \\
\hline Perceptual -Motor Abilities & 0.237 & 462.610 & 0.000 \\
Neurological-Psychological Skills & 0.698 & 59.595 & 0.000 \\
Attention Deficit, Hyperactivity and & & & \\
Impulsivity & & & \\
\hline
\end{tabular}

Table 3 shows that there are statistical differences for all three scales indicating they are capable of distinguishing between normal students and students with learning disabilities.

To answer the second question, it is important to examine the differences in the grade averages of normal students and the students with learning disabilities on the three scales, with regard to gender. Using means and standard deviations, we examined the grades of students with learning disabilities on the three scales, as shown in Table 4.

Table 4. Means and standard deviations of the grades for students with learning disabilities on the three scales

\begin{tabular}{lllllll}
\hline Scale Sample & \multicolumn{2}{c}{ Males (36) } & \multicolumn{3}{c}{ Females (32) } & \multicolumn{2}{c}{ All (68) } \\
\cline { 2 - 7 } & $\mathrm{M}$ & $\mathrm{SD}$ & $\mathrm{M}$ & $\mathrm{SD}$ & $\mathrm{M}$ & $\mathrm{SD}$ \\
\hline $\begin{array}{l}\text { Perceptual - Motor } \\
\text { Abilities }\end{array}$ & 2.490 & .397 & 2.553 & .484 & 2.521 & 0.438 \\
$\begin{array}{l}\text { Neurological } \\
\text { Psychological Skills }\end{array}$ & 2.752 & .490 & 2.588 & .508 & 2.579 & 0.495 \\
$\begin{array}{l}\text { Attention Deficit, } \\
\text { Hyperactivity and }\end{array}$ & 3.560 & .688 & 3.688 & .563 & 3.491 & 0.638 \\
Impulsivity & & & & & & \\
\hline
\end{tabular}

To check if the average grades of the participants on the three scales can distinguish students with learning disabilities according to gender, distinguished results of their grades have been examined by the three scales as illustrated in Table 5. 
Table 5. Distinguished results of grades examined by three scales

\begin{tabular}{llll}
\hline Scales & $\begin{array}{l}\text { Test Value } \\
\text { Wilks Lamda }\end{array}$ & F Value & $\mathrm{p}$ \\
\hline $\begin{array}{l}\text { Perceptual-motor } \\
\text { abilities }\end{array}$ & .995 & .016 & 0.567 \\
$\begin{array}{l}\text { Neurological } \\
\begin{array}{l}\text { Psychological Skills } \\
\text { Attention Deficit, }\end{array}\end{array}$ & 1.000 & .082 & 0.900 \\
$\begin{array}{l}\text { Hyperactivity and } \\
\text { Impulsivity }\end{array}$ & .967 & 2.277 & 0.136 \\
\hline
\end{tabular}

Table 5 shows that there is no statistical difference in the three scales indicating they are incapable of distinguishing between normal students and students with learning disabilities by gender.

\section{Discussion}

Returning to our research questions, we first sought to examine the differentiating evidence for scores of students with learning disabilities in the first cycle of school (1-4) on the Perceptual-Motor abilities Scale, ADHD Scale, and psychological and IQ Skills Scale according to their learning disability classification. According to discriminate analysis, the results show that there is a negative significant correlation among students' attention deficit followed by hyperactivity, impulsivity and students' perceptual-motor abilities and their neurological skills. This indicates that when participants' grades increase on perceptual-motor abilities and a neurological-psychological test, their attention improves and their hyperactivity and impulsivity decrease. Hence, the children who have not received orientation programs in cycle one (which enhances their perceptual-motor abilities and their neurological-psychological skills) might lead to a child with learning disabilities. Indeed, the educational process, reading and writing in particular, requires students to have perceptual-motor abilities that develop within him/her continually through time intervals. When a child is behind his/her normal peers in all the above skills and abilities for either physiological reasons or sickness, the child falls behind in his/her learning processes and understanding abilities.

In addition, there are some theories to explain the relationship between growth of children's perceptual-motor abilities and their process of learning during childhood. These theories state that there is a considerable percentage of children suffering disabilities related to learning in school, such as difficulty in reading and writing. They may also have difficulty while performing some school skills or may suffer reduction in their Dyslexia. Thus, it becomes apparent that like those children have deficiency in the growth of their perceptual-motor abilities. In most cases, these children are either low-achievers or suffering from learning disabilities.

Lerner (2000) affirms that perceptual-motor abilities problems are mostly concerned with students suffering learning disabilities. Moreover, children suffering from problems related to their serious and light motor activities also face academic and non-academic challenges. Lowentahal's (2002) study supports Lerner's and lays out the fact that students who suffer learning problems are characterized with attention deficiency negatively related to their cognitive abilities.

Another interpretation could be that children's academic cognitive inability, who suffer from hyper activity, have a neurological disorder (Cantwell \& Baker, 1991; DeMarie et al., 2002). According to this, other researchers have shed light on the importance of investigating developmental abilities and neurological functions (Lowenthal, 2002; Mazzocco, 2005). They found that children who suffer learning disabilities are characterized with attention and memory deficiency and weakness in their kinetic-sensory comprehension.

In the current study, it becomes clear that the three scales were able to distinguish between normal students and students with learning difficulties. These scales work in correspondence with the theoretical lexis and the previous studies which confirm the statistical differences between normal students and students with learning difficulties. Hence, we can benefit from these results to diagnose these children in early stages, to decrease the rate in higher stages of education and to introduce suitable strategies for treatment. The results_mentioned above are in parallel with other studies with regard to inability to control attention (Leung \& Conitolly, 1994; Martinussen, Tannock, McInnes, \& Chaban, 2006; Mayes \& Calholl, 2007), with short-term memory skills (Swanson, Xinhua, \& Jerman, 2009), and low-achievement (Bender, 2002; Jerry, 2000). Furthermore, Fabian and Jacobs' study (1981) found statistical differences between students with learning disabilities suffering from 
dyslexia and normal students when they had a counting test using fingers. Normal students were better in cognitive processes.

The second research question of the current study concerned differentiating evidence for learning disabilities students' scores in the first cycle of school (1-4) on the Perceptual-Motor abilities Scale, ADHD Scale, and psychological and IQ Skills Scale according to gender. The results indicate that the three scales used in this study were unable to distinguish between students with learning disabilities according to gender. One interpretation of this result could be that students who suffer attention deficiency, hyperactivity and dispersion tendency to external stimulants are prominent features of those students. Regardless of their gender, they do not distinguish between stimuli and children and quickly get distracted from watching the same stimulus continuously. Usually, it does not exceed a few minutes. They automatically and easily tend to enjoy external stimuli, like looking through a class window or keeping an eye on other children's movements. Generally, we find these children face challenges in concentrating on tasks and in finding a way to achieve the task. Thus, it becomes difficult for them to learn new skills (Mayes, Calhoun, \& Crowell, 2000).

The results of this study agree with other Arab studies in this area. For example, Alnajdawi (1993) found no statistical differences in students with learning disabilities, in relation to attention, motor skills, cognition, and memory, regardless of their gender. In addition, the results of the current study are similar to Demonet, Tayler and Chaix's (2004) study. Their study found that students with learning difficulties, with dyslexia, have deficiency in their cortical processing, when compared with their normal peers. However, the absence of a difference between students with learning difficulties with regard to gender is related to psychological and neurological tests.

In addition, our study confirms the results of Anzelmo-Skelton (2006) and Moore et al. (1996). These researchers assumed that the absence of statistical difference between these students may be due to the fact that the three scales used in this study did not take into consideration gender difference. Thus, the outcomes of the participants' answers correspond with its main purpose.

\section{Conclusion}

There is a need to conduct more research to check the capability of the three scales; future research can be conducted using other samples to examine the ability to distinguish between normal students and students with learning disabilities. We recommend using the three scales on students with learning disabilities for early examination. There is a need to conduct a similar study, with other scales, for better examinations.

\section{References}

Alloway, T., \& Passolunghi, G. (2006). Working memory and arithmetic learning disability. In T. P. Editor (Ed.), Working memory and developmental disorders (pp. 113-138). New York, NY: Psychology Press.

Anderson, J. E. (2000). Self efficacy and social skills as predictors of social competency of students with learning disabilities (Unpublished doctoral dissertation). Texas A\&M University.

Anzelma-Skelton, A. (2006). Learning style ,strategy use, personalization of mathematical word problems and responses of students with learning disabilities. International Journal of Special Education, 21(1), 1-19.

Ashbaker, A. H., \& Swanson, H. L. (1996). Short-term memory and working memory operations and their contribution to reading in adolescents with and without learning disabilities. Journal Learning Disabilities, 11(4), 61-87.

Bader, M., \& Eddin, S. M. (2001). A proposed program for capacity development sense-motor and principles of reading by studying physical education for first graders. Journal of Science and Arts Sports, Cairo, 14 to 15(4), 64-81.

Barkley, R. A., \& Murphy, K. R. (2006). Attention-Deficit Hyperactivity Disorder: A clinical workbook. Location: Guilford Press.

Barratt, S. (2004). The special educators. London: Sage.

Beaton, A., Edward, R., \& Peggie, A. (2006). Dyslexia and across-hands finger localization deficits. Neuropsychological, 44, 326-334. http://dx.doi.org/10.1016/j.neuropsychologia.2005.04.017

Bender, W. N. (2001). Learning disabilities: Characteristics, identifications, and teaching strategies (4th ed). U.S.A.: Allyn \& Bacon.

Bender, W. N. (2002). Differencing instruction for students with learning disabilities. U.S.A. Coming Press Inc. 
Buckner R. L., \& Wheeler M. E. (2001). The cognitive neuroscience of remembering. Nature Reviews Neuroscience, 2(9), 624-634. http://dx.doi.org/10.1038/35090048

Cantwell, D. P., \& Baker, L. (1991). Psychiatric and developmental disorders in children with communication disorder. Washington, DC: American Psychiatric Association.

Claudia V. (2009). Impact of working memory deficits on academic achievement in adolescents with Attention-Deficit/Hyperactivity Disorder. University of Toronto. Retrieved from https://tspace.library.utoronto.ca/bitstream/1807/18087/1/Vexelman_Claudia_200911_MA_thesis.pdf

Couillet, J., Leclercq, M., Moroni, C., \& Azouvi, P. (2002). Neuropsychology de attention, Solal, Paris in Allowazei, Ruzicka (2009). Study of neuropsychiatric my job selective attention and working memory. Studies Alertofinua science and neuropsychology, Algeria, X(1), 23-40. Retrieved from http://www.baseeracenter.com/portal/doc/artaphonie1.pdf

Cullatta, R., \& Tonpkins, J. (2003). Fundamentals of Special Education, What every teacher needs to know. Ohio: Merrill Prentice- Hall.

DeMare, D., Denk, L., \& Ernsthausen, C. (2003). Working with the family of a child with attention deficit hyperactivity disorder, Pediatric Nursing, 29(4), 302-308.

Demonet, J., Taylor, M. J., \& Chaix, Y. (2004). Dyslexics, language disorders, learning disabilities, readingremedial teaching. Lancet, 363(9419), 1451-1461.

Emerson, E., \& Baines, S. (2011). Health inequalities and people with learning disabilities in the UK. Tizard Learning Disability Review, 16(1), 42-56. http://dx.doi.org/10.5042/tldr.2011.0008

Exner, S. (2010). An examination of the relationships among learning disabilities, (ADHD). Academic selfefficacy, effort, self awareness, and academic achievement in post second students (Unpublished doctoral dissertation). University of Alfred, Location.

Fabian, J. J., \& Jacobs, U. W. (1981). Discrimination of neurological impairment in the learning disabled adolescent. Journal of Disabilities, 14(10), 594-596.

Hassan, A. S. (2007).Validity and reliability indices for Arabic version of Purdue perceptual- motor survey, using a sample of students at Muscat. Gordian Journal in Educational Science, 3(4), 331-349.

Herbert, M. (1999). Clinical Child Psychology, Social learning development and behavior (2nd ed.). New York: John Wiley \& Sons.

Heward, W. (2006). Exceptional children: An introduction to special education (8th ed.). Upper Saddle River, NJ: Merrill/Prentice Hall.

Job, J. M., \& Klassen, R. M. (2012). Predicting performance on academic and non-academic tasks: A comparison of adolescent with and with out: Learning disabilities. Contemporary Educational Psychology, 37(2), 162-169. http://dx.doi.org/10.1016/j.cedpsych.2011.05.001

Kelly, E. (2009). Encyclopedia of attention deficit hyperactivity disorder. California: Greenwood Press.

Kindle, K. J. (2009). Vocabulary development during read-aloud: Primary practices. The Reading Teacher, 63(3), 201-211. http://dx.doi.org/10.1598/RT.63.3.3

Learner, J. W. (2000). Learning disabilities: Theories, diagnosis and teaching strategies (8th ed.). Boston: Houghton Mifflin Company.

Learner, J. W. (2000). Learning disabilities. U.S.A: Houghton Mifflin Company.

Leung, P., \& Connolly, K. (1994). Attentional difficulties in hyperactive conduct disordered children 'A processing Deficit'. Journal of Child Psychology and Psychology, 35, 1229-1245. http://dx.doi.org/10.1111/j.1469-7610.1994.tb01231.x

Levine, H. S. (2002). Working memory after traumatic brain injury in children. Annals of Neurology, 52(1), 82-88. http://dx.doi.org/10.1002/ana.10252

Levine, M. (2002). Educational care: A system for understanding and helping children with learning differences at home and in school (2nd ed.). Location: Academic Press.

Liddell, G., \& Rasmussen, C. (2005). Memory profile of children with nonverbal learning disability. Learning Disabilities Research and Practice, 20(3), 137-141. http://dx.doi.org/10.1111/j.1540-5826.2005.00128.x 
Lord-Maes, J., \& Obrzut, J. E. (1996). Neuropsychological consequences of traumatic brain injury in children and adolescents. Journal of Learning Disabilities, 29, 609-617. http://dx.doi.org/10.1177/002221949602900605

Lowenthal, B. (2002). Precursor's of learning disabilities in the inclusive preschool. Illinois: University of Illinois.

Maniadaki, K., \& Kakouros, E. (2011). Attention problems and learning disabilities in young offenders in detention in Greece. Psychology, 2(1), 53-59. http://dx.doi.org/10.4236/psych,2011.21009.

Martinussen, R., Tannock, R., McInnes, A., \& Chaban, P. (2006). TeachADHD: Teacher's Resource Manual. Toronto, Canada: TVOntario.

Mayes, S. D., \& Calhoun, S. L. (2007). Predictors of academic achievement in children with attention deficit/hyperactivity disorder. School Psychology Quarterly, 22(2), 234-249. http://dx.doi.org/ $10.1037 / 10045$

Mazzocco, M. (2005). Challenges in identifying target skills for math disabilities screening and intervention. Journal of Learning Disabilities, 28(4), 318-323. http://dx.doi.org/10.1177/00222194050380040701.

McLeskey, J., \& Waldron, N. (2011). Educational programs for elementary students with learning disabilities: Can they be both effective and inclusive? Learning Disabilities Research \& Practice, 26(1), 48-57. http://dx.doi.org/10.1111/j.1540-5826.2010.00324.x

Medwid, D. W. (2002). Kid-Friendly parenting with deaf and hard children. Washington, Gallaudet University Press.

Monastra, V. (2008). Unlocking the potential of patients with ADHD: A model for clinical practice. Washington DC: American Psychological Association. http://dx.doi.org/10.1037/11665-000

Morrow, L. M. (2005). Helping children for reading and writing skills: The role of family in teaching reading and writing. The State University of New Jersey: Rutgers.

Nasreen, A. (1995). A comparative study between the behavioral characteristics, linguistic and academic for children with learning disabilities and children in a sample of ordinary Jordanian (Unpublished master's thesis). University of Jordan, Jordan.

O'Connel, J., \& Casale, K. (2004). Attention deficits and heading loss: Meeting the challenge (References). The Volta Review, 104(4), 257-271.

Rief, S. (2008). The ADD/ ADHD checklist: A practical reference for parents \& teacher (2nd ed.). San Francisco: Jossey-Bass.

Rohl, M., \& Pratt, C. (1995). Phonological awareness, verbal working memory and the acquisition of literacy. Reading and Writing: An Interdisciplinary Journal, 7(4), 327-360. http://dx.doi.org/10.1007/BF01027723

Ruby, A. O. (1991). To measure perceptual motor abilities of the children in the framework of the theory of Newell Kayvart. Qatar University, Center for Educational Research.

Shapiro, D. R., \& Ulrich, D. A. (2002). Expectancies, Activity Quarterly, 19(3), 318-343.

Smith, D. (2004). Substance use attitude and behavior of students with learning disabilities (Unpublished doctoral dissertation). Ohio State University, Ohio.

Swanson, L. (1994). Short-term memory and working memory: Do both values, and perceptions of physical competence of children cith and without learning disabilities. Adapted Physical contribute to our understanding of academic achievement in children and adults with learning disabilities. Journal Learning Disabilities, 27(1), 34-50. http://dx.doi.org/10.1177/002221949402700107

Swanson, H. L., \& Ashbaker, A. H. (2000). Working memory, short-term memory, articulation speed, word recognition, and reading comprehension in learning disabled readers: Executive and/or articulatory system? Intelligence, 28, 1-30. http://dx.doi.org/10.1177/0022219409331958

Swanson, H. L., \& Jerman, O. (2009). The influence of working memory on reading growth in subgroups of children with reading disabilities. Journal Experimental Child Psychology, 96, 249-283. http://dx.doi.org/10.1016/j.jecp.2006.12.004 
Swanson, H. L, Xinhua, Z., \& Jerman, O. (2009). Working memory, short memory, and reading disabilities: A selective meta-analysis of the literature. Journal of Learning Disabilities, 42, 260-287. http://dx.doi.org/10.1177/0022219409331958

Turkington, C., \& Harris, J. (2006). The encyclopedia of learning disabilities (2nd ed.). New York: Facts on File,Inc.

U.S. Department of Education, National Center for Education Statistics. (2006). The Condition of Education 2006 (NCES 2006-071). Washington, DC: U.S. Government Printing Office. Retrieved from http://nces.ed.gov/pubs2006/2006071.pdf.30/3/2014

Waldron, K., \& Saphire, D. (1992). Perceptual and academic patterns of learning disabled/gifted students. Perceptual and Motor Skills, 74, 599-609. http://dx.doi.org/10.2466/pms.1992.74.2.599

Webster, R. (2004). Short-term memory in mathematics'-proficient and mathematics disabled students as a function of in put-modality / out put-modality pairing. Journal of Special Education, 72(5), 277-283.

Westendorp, H., Hartman, E., Houwen, S., Smith, J., \& Visscher, C. (2011). The relationships between gross motor skills and academic achievement in children with learning disabilities. Research in developmental disabilities, 32(6), 2273-2779. http://dx.doi.org/10-1016/j.ridd.2011.05.032.

Williams, S., \& McGee, R. (1994). Reading attainment and juvenile delinquency. Journal of Child Psychology and Psychiatry, 35, 441-461. http://dx.doi.org/10.1111/j.1469-7610.1994.tb01733.x

Womack, S., A. (2011). Literature- based social skills instruction: A strategy for students with learning disabilities. Intervention in School and Clinic, 46(3), 157-164. http://dx.doi.org/10.1177/1053451210378164

Zarghi, A., Mehrinejad, S. A., Zali, A., \& Remezankani, Z. (2012). Memory performance among children with ADHD. Basic and Clinical, 3(4), 68-74.

Zhang, J., \& Zhang, D, (2003). Perceptual motor performances of children with learning and behavioral disorders (Special Populations). Research Quarterly for Exercise and Sport, 83(1), 32-45.

\section{Copyrights}

Copyright for this article is retained by the author(s) with first publication rights granted to the journal.

This is an open-access article distributed under the terms and conditions of the Creative Commons Attribution licence (http://creativecommons.org/licenses/by/3.0) 